\title{
Responsiveness of buckwheat varieties to foliar applications by microfertilizer under forest steppe of the volga region
}

\author{
Lilia R. Klimova ${ }^{1, *}$, Fanusya Z. Kadyrova ${ }^{1}$, Rogat V. Minikaev ${ }^{1}$ and Alsu T. Khusnutdinova ${ }^{2}$ \\ ${ }^{1}$ Kazan State Agrarian University, Kazan, 420011, Republic of Tatarstan, Russia \\ ${ }^{2}$ TatRIA of FRC of Kazan SC of the RAS, Kazan, 420059, Republic of Tatarstan, Russia
}

\begin{abstract}
The yields of modern intensive varieties of buckwheat in arid regions are highly susceptible to adverse hydrothermal growing conditions. The selection of optimal compositions and technologies for using modern agrochemicals that provide an adaptogenic effect and a favourable vegetation regime of plants can be an effective way to stabilize the grain production of this warm-loving but the drought-resistant crop. Scientists have poorly studied these issues and the issues of efficient use of mineral nutrition resources in buckwheat. They studied the responsiveness of buckwheat varieties, that differ in the morphological and biological characteristics of plants, to the foliar application by Yara concentrated complex water-soluble fertilizers containing macro- and microelements. The data obtained indicate the presence of varietal specificity, which manifests itself to varying degrees of plant responsiveness to foliar application in the formation of leaf area, grain yield and quality indicators of the crop. The authors made conclusions about the preferred dates for foliar application with the studied Yara complex micronutrient fertilizers. When the foliar application of microelements in the phase of the beginning of grain formation, the K-850 cultivar had the highest yield and the best quality parameters of grains. For the K-899 cultivar, the application in the russeting phase was most effective for grains and affected the best plumpness of the grains. The more powerful morphological potential of Batyr plants was not realized by an adequate increase in yield for the performed feeding. The authors observed a slight tendency to decrease the crude protein content in grains during the foliar application which is probably due to the inverse correlation of this trait with the formation rate of the organic mass of plants.
\end{abstract}

\section{Introduction}

Modern breeding programs focus on creating complexly valuable varieties with a diverse morphophysiological structure of plants. Accordingly, different morphobiotypes have specific requirements for growing conditions, and the cultivation efficiency of biologically different varieties can be ensured through a differentiated approach to cultivation technologies. It is especially urgent to create optimal, targeted agricultural technologies for such a crop as buckwheat forming a large organic mass in a short period of vegetation and, therefore, requiring balanced mineral nutrition of plants.

Modern crop production widely uses foliar applications as a method of increasing the size and quality of crops. The work of many researchers revealed the high efficiency of various types of fertilizers, as well as methods for their application [1-4]. The publications provide data on the positive effect of microelements on buckwheat productivity [5, 7]. In particular, they revealed a positive effect of micronutrient fertilizers on the photosynthetic potential of buckwheat plants [6]. Scientists proved the effectiveness of the foliar application of selenium-containing fertilizers and solutions of microelements to the soil on the example of buckwheat (Fagopyrum esculentum, Moench), in particular $[8,9]$.

The market of modern mineral nutrition resources of plants has many offers of various agrochemicals containing a complex of macro- and micronutrient fertilizers, biologically active compounds. Meanwhile, scientists have poorly studied the technology of their use on buckwheat, while in unfavourable hydrothermal conditions of vegetation their scientifically-based application can solve the problem of increasing buckwheat yields.

Our research aimed to study the responsiveness of various buckwheat genotypes to foliar applications with micronutrient fertilizers.

\section{Materials, methods and experimental conditions}

We set up the experience in studying the responsiveness of buckwheat varieties to foliar applications on the experimental field of the Agronomy Department of Kazan State Agrarian University, on grey forest soil with a humus content of $3.8 \%$, with a high phosphorus content $(287 \mathrm{mg}$ per $100 \mathrm{~g}$ of soil) and high potassium

* Corresponding author: li21@mail.ru 
content (152 $\mathrm{mg}$ per $100 \mathrm{~g}$ of soil), with the acidity of $6.3 \mathrm{PH}_{\text {sol. }}$.

We repeated the experiments four times on plots with an area of $6.6 \mathrm{~m}^{2}$. The technology of tillage and sowing is generally accepted for the Republic of Tatarstan. We sowed on May 20 in an ordinary way with a seeding rate of 2.0 million pcs. seed per hectare. Two-factor field experience included the following options:

- A-grade factor: $A_{1}$ - Batyr (standard), $A_{2}-$ cultivated variety K-850, $\mathrm{A}_{3}$ - cultivated variety K-899;

- factor B - foliar application by a complex of micronutrient fertilizers according to the phases of plant development: $\mathrm{B}_{1}$ - control, $\mathrm{B}_{2}$ - micronutrient treatment at the beginning of the flowering phase, $\mathrm{B}_{3}-$ micronutrient treatment at the beginning of grain formation phase, $\mathrm{B}_{4}-$ micronutrient treatment at the beginning of russeting phase.

For the study, we took two cultivated varieties K-850 and K-899, the original forms of which included in the hybrid populations differed in morphostructural and biological features.

Composition of the hybrid population $\mathrm{K}-850$ has predominantly medium-sized morphotypes with a fasciated stem, limited branching and large apical inflorescences which contributes to more friendly flowering and intensive grain formation in the first half of flowering. The composition of the $\mathrm{K}-899$ population was formed from materials for selecting fascinated curlyshaped forms (with uneven growth of the intercalar meristem) with well-developed branching at the first-order level and almost complete reduction of second-order shoots. Due to the reduction of branching, this morphobiotype also has a high friendliness of grain formation.

For comparison, as a control, we used the Batyr cultivar of the Tatar Research Institute of Agriculture admitted to cultivation in the Middle Volga Region, related to the Krasnostreletsky variety by morphological and biological characteristics according to the classification of VIR (N.I.Vavilov Research Institute of Plant Industry) [10].

In our studies, we used Yara concentrated complex water-soluble fertilizers containing macro- and microelements. For the foliar application, we used the following scheme. The first spraying at the beginning of the phase: YaraVita AGRIPHOS 1 l/ha + Yara KRISTALON brown $2 \mathrm{~kg} / \mathrm{ha}+$ Carbamide $5 \mathrm{~kg} / \mathrm{ha}$. The second spraying was 2 days after the first: YaraVita MANTRAC PRO 1 1/ha + YaraVita BORTRAC 2 1/ha. We conducted buckwheat harvesting in a single phase with preliminary desiccation of Tornado crops ( $2 \mathrm{l} / \mathrm{ha})$.

Meteorological conditions in 2019 had instability of hydrothermal conditions for buckwheat vegetation.

The second and third decades of May had high daytime temperatures and a lack of solar insolation. During the formation of seedlings, the weather was warm with an abundance of rainfall. Despite the favourable daytime temperatures, the emergence of seedlings was delayed due to the formed soil crust after heavy rains. The daily temperature of the second decade varied in the range of $21.8-15.8{ }^{\circ} \mathrm{C}$, in the third decade of May it was from 21.1 to $5.3^{\circ} \mathrm{C}$.
The average daily temperatures established in June were close to normal, however, precipitation stopped in the first 20 days of June during the formation of the habitus of plants.

The temperature regime in July during the active formation of the reproductive organs had a certain decrease in average daily temperatures compared with the norm. During this period, we observed low night temperatures up to $8-9{ }^{\circ} \mathrm{C}$, which corresponds to the biological minimum for buckwheat plants. Rainfall precipitation exceeded the norm by $45-89 \%$. Meanwhile, we need to note that low average daily air temperatures combined with increased cloudiness and high atmospheric humidity prolonged the flowering of buckwheat in all studied variants.

\section{Results and discussion}

One of the criteria for the structure of the crop yield is the number of productive plants per unit area. According to the data in Table 1, the varieties were on the same level in field germination. The heavy rains and the resulting soil crust significantly reduced the field germination of plants. By the end of the growing season, the varieties showed differences in plant safety. These varietal differences indicate the manifestation of their environmental resistance to unstable hydrothermal conditions during the growing season of plants. The K-899 cultivar $(98 \%)$ had maximum environmental sustainability, which exceeded the zoned standard by $10 \%$.

Table 1. Ecological sustainability of buckwheat varieties (2019)

\begin{tabular}{|l|l|l|l|}
\hline \multicolumn{1}{|c|}{ Indicators } & \multicolumn{1}{c|}{$\begin{array}{c}\text { Batyr } \\
\text { (standard) }\end{array}$} & \multicolumn{1}{c|}{ K-850 } & K-899 \\
\hline $\begin{array}{l}\text { The number of plants in } \\
\text { seedlings }\end{array}$ & 128 & 134 & 132 \\
\hline Field germination,\% & 64 & 67 & 66 \\
\hline $\begin{array}{l}\text { The number of plants } \\
\text { before harvesting }\end{array}$ & 113 & 127 & 129 \\
\hline $\begin{array}{l}\text { The ecological } \\
\text { sustainability of the plants, } \\
\%\end{array}$ & 88 & 94 & 98 \\
\hline
\end{tabular}

The photosynthetic activity of leaves determined the accumulation of an organic mass of plants during growth and development. Given the morphological and biological differences of the studied varieties, we were interested in assessing the effect of foliar applications on the formation rate of the leaf surface of plants. Table 2 shows the effect of foliar applications on the formation of the leaf surface of the studied varieties. The buckwheat genotypes formed the leaf surface in different ways responding to fertilizing in the phase of the beginning of flowering (Table 2).

According to the data presented, the promising cultivar K-899 and K-850 without micronutrient cultivation are superior to the standard variety of Batyr in leaf surface area of plants by 17.3 and $58.1 \%$. This difference in the leaf supply of plants is due to varietal characteristics determining more commercially available 
leaf sizes of the studied cultivars. Given the density of the stalk, this difference in experience was $33.9 \%$ in the variety K-899, and $77.8 \%$ in the variety $\mathrm{K} 850$.

Table 2. The effect of foliar applications on the size of the leaf surface of buckwheat varieties (2019)

\begin{tabular}{|c|c|c|c|c|c|}
\hline \multirow{3}{*}{$\frac{\vec{d}}{\frac{\pi}{\pi}}$} & \multirow{3}{*}{ 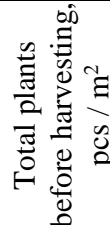 } & \multicolumn{4}{|c|}{$\begin{array}{l}\text { Leaf area at the beginning of grain } \\
\text { formation }\end{array}$} \\
\hline & & \multicolumn{2}{|c|}{$\begin{array}{l}\text { on variants without } \\
\text { foliar applications }\end{array}$} & \multicolumn{2}{|c|}{$\begin{array}{l}\text { on variants with foliar } \\
\text { applications }\end{array}$} \\
\hline & & $\mathrm{m}^{2} / 1$ plant & $\mathrm{m}^{2} / \mathrm{m}^{2}$ & $\mathrm{~m}^{2} / 1$ pla & $\mathrm{m}^{2} / \mathrm{m}^{2}$ \\
\hline $\mathrm{Ba}$ & 113 & & & & \\
\hline K-8 & 127 & & 88 & & 2.209 \\
\hline K-899 & 129 & 0.0115 & 1.483 & 0.0157 & 2.025 \\
\hline
\end{tabular}

Foliar applications activated the formation of a leaf surface in the studied varieties. The highest growth was in the Batyr variety $(95.9 \%$ to the variant without treatment). This is due to the unlimited growth potential of plants of this variety leading to the formation of unproductive branching at the level of second and thirdorder shoots.

The K-850 and K-899 cultivars formed on the inclusion of fasciated forms in the initial populations possess genetically determined growth and, by the beginning of grain formation, stop the formation of new metamers and, accordingly, the formation of new leaves. The growth of the leaf surface in these varieties for the variant without foliar application was only 12.3 and $36.5 \%$.

The studied varieties showed a different degree of responsiveness to the foliar application during the formation of buckwheat yield (Fig. 1).

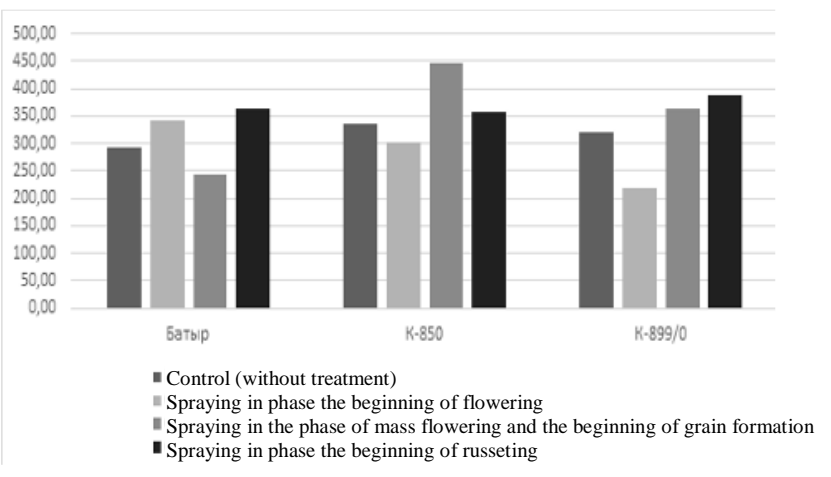

Fig. 1. The effect of foliar application in various phenological phases on the yield of buckwheat grain, $\mathrm{g} / \mathrm{m}^{2}$

Cultivar K-850 had the highest yield with foliar application of microelements in the phase of the beginning of grain formation. The addition of grain to the variety without treatment amounted to $32.6 \%$, and the Batyr standard during processing in this phase was $83 \%$.

For the K-899 cultivar, the most effective was the application in the russeting phase, which undoubtedly affected the best plumpness of the grains (see Table 3). The excess of the yield of this variety with fertilizer over the variety without fertilizing in this variety was $11.5 \%$. With the introduction of microelements in the phase of the beginning of flowering, the yield of this cultivar markedly decreased relating to all variants of the experiment.

The Batyr variety had the lowest yield when cultivated without foliar applications. This variety gave the maximum effect when micronutrient fertilizers were introduced in the phase of russeting.

An analysis of the qualitative characteristics of the grains showed that the revealed differences in yield are also due to the technological quality parameters of the studied varieties (Table 3).

Table 3. The effect of foliar applications on the quality indicators of the buckwheat crop (2019)

\begin{tabular}{|c|c|c|c|c|}
\hline \multirow[t]{2}{*}{ Indicators } & \multirow{2}{*}{ Spraying time } & \multicolumn{3}{|c|}{$\begin{array}{c}\text { Characteristic values by } \\
\text { variety }\end{array}$} \\
\hline & & Batyr & K-850 & K-899 \\
\hline \multirow{4}{*}{$\begin{array}{l}\text { Weight of } \\
1,000 \\
\text { grains, g }\end{array}$} & Control & 33.4 & 30.9 & 32.3 \\
\hline & $\begin{array}{l}\text { Beginning of } \\
\text { flowering }\end{array}$ & 35.6 & 33.2 & 31.5 \\
\hline & $\begin{array}{l}\text { Beginning of } \\
\text { grain } \\
\text { formation }\end{array}$ & 31.8 & 34.6 & 28.1 \\
\hline & $\begin{array}{l}\text { Beginning of } \\
\text { russeting }\end{array}$ & 35.1 & 34.7 & 30.5 \\
\hline \multirow{4}{*}{$\begin{array}{c}\text { Grain size, } \\
\mathrm{g} / \mathrm{l}\end{array}$} & Control & 555.3 & 532.0 & 528.0 \\
\hline & $\begin{array}{l}\text { Beginning of } \\
\text { flowering }\end{array}$ & 575.5 & 518.0 & 586.0 \\
\hline & $\begin{array}{l}\text { Beginning of } \\
\text { grain } \\
\text { formation }\end{array}$ & 548.5 & 555.7 & 574.0 \\
\hline & $\begin{array}{l}\text { Beginning of } \\
\text { russeting }\end{array}$ & 563.7 & 554.7 & 594.0 \\
\hline \multirow{4}{*}{$\begin{array}{l}\text { Crude } \\
\text { protein } \\
\text { content in } \\
\text { grain, \% }\end{array}$} & Control & 12.21 & 12.10 & 11.36 \\
\hline & $\begin{array}{l}\text { Beginning of } \\
\text { flowering }\end{array}$ & 10.70 & 11.75 & 11.34 \\
\hline & $\begin{array}{c}\text { Beginning of } \\
\text { grain } \\
\text { formation } \\
\end{array}$ & 10.12 & 11.82 & 11.67 \\
\hline & $\begin{array}{l}\text { Beginning of } \\
\text { russeting }\end{array}$ & 11.86 & 11.63 & 11.19 \\
\hline
\end{tabular}

The Batyr variety was most large-grained in the experiment. The weight of 1000 grains of this variety ranged from 31.8 to $35.6 \mathrm{~g}$ depending on the spraying time. The grain plumpness (nature) is in the range of $548.5 \ldots 575.5 \mathrm{~g} / 1$. We should pay attention to the fact that these quality parameters of the Batyr variety decreased with other variants, as well as the yield with the introduction of microelements at the beginning of grain formation.

According to table 3 , the K-899 cultivar proved to be the most demanding on the mineral nutrition of plants during the formation of grains, whose natural weight during feeding was steadily increasing. Application in the phase of the beginning of russeting gave the maximum increase in the grain nature $(66 \mathrm{~g} / \mathrm{l})$.

In terms of plumpness and weight of 1000 grains, the K-850 cultivar was of intermediate importance and formed the best quality parameters during application in the phases of grain formation and russeting.

In terms of crude protein content in grain, the largergrained varieties Batyr and K-850 had similar values (12.21-12.10\%), the K-899 cultivar was slightly inferior to them in this indicator $(11.36 \%)$. There was a slight 
tendency to a decrease in the crude protein content in grains during the foliar application, which may be due to the inverse correlation of this trait with the rate of formation of organic mass of plants.

\section{Conclusion}

The data obtained indicate the presence of varietal specificity, which manifests itself to varying degrees of plant responsiveness to foliar application in the formation of leaf area, grain yield and quality indicators of the crop.

The authors identified the preferred dates for foliar application with the studied complex micronutrient fertilizers. The micronutrients of the Batyr variety and the K-899 cultivar were effective at the beginning of russeting, which provided a $23 \%$ increase in yield relative to the untreated option and the most optimal parameters of plumpness and weight of 1000 grains. The treatment of the K-850 cultivar was effective at the beginning of grain formation, at which the yield exceeded the option without treatment by $32 \%$.

We noted a slight tendency to a decrease in the content of crude protein in the grains of the studied varieties with foliar application. Cultivar K-899 was the most flexible to the growing conditions. Ecological sustainability of plants of this variety was maximum.

\section{References}

1. Z.I. Glazova, V.M. Novikov, Evaluation of some elements of agricultural technology buckwheat, Agricult., 5, 17-21 (2012)
2. Z.I. Glazova, The effectiveness of the use of organomineral complexes for foliar application of buckwheat, Grain and leguminous crops, 2(30), 101-107 (2019)

3. O.A. Sokolov, Mineral nutrition of plants in soil conditions (for example, buckwheat) (Nauka, Moscow, 1980), $193 \mathrm{p}$.

4. F.Z. Kadyrova, A.V. Popov, Ways to increase buckwheat productivity in arid regions of Russia, Achievements of sci. and technol. of the agro-indust. Complex, 3, 9-11 (2007)

5. I.Sh. Fatykhov, Buckwheat, Bull. of the Izhevsk State Agricult.1 Acad., 2(8), 52-54 (2006)

6. S.I. Kokonov, I.R. Salyakhov, Z.M. Khaertdinova, Yield of buckwheat Saulyk depending on pre-sowing seed treatment, in: Mater. of Univer. Student Conf. "Knowledge of the young - a new century" pp. 1213 (Vyatka State Agricult. Acad., Kirov, 2005)

7. Z.I. Glazova, I.M. Mikhailova, Productivity and technological properties of buckwheat grain depending on the variety and fertilizers, Legumes and cereals, 1(25), 87-91 (2018)

8. Y. Jiang et al., Effects of selenium fertilizer on grain yield, se uptake and distribution in common buckwheat (Fagopyrum esculentum Moench), Plant, Soil and Environment, 61(8), 371-377 (2015)

9. C. Liu, et al., Trace element water improves the antioxidant activity of buckwheat (Fagopyrum esculentum Moench), J. of Agricult.l and Food Chem., 55(22), 8934-8940 (2007)

10. A.S. Krotov, Cultural Flora of the USSR, vol. 3 (Kolos, Leningrad, 1975), 364 p. 